\title{
Identificación de apoptosis liquen plano oral con caspasa 3.
}

\section{Apoptosis identification in oral lichen planus with caspase 3.}

\author{
Liset Eliana Osnaghi Díaz Colodrero, * Víctor Fernández, ${ }^{\ddagger}$ \\ Teresa Pombo, ${ }^{\S}$ Claudio Modenutti," María Susana Briend
}

\section{RESUMEN}

Las enfermedades autoinmunes tienen múltiples manifestaciones en estomatología, entre las más frecuentes se encuentra el liquen plano oral (LPO), se trata de una enfermedad crónica con manifestaciones clínicas en piel y mucosas. Se agrupa en dos formas anatomoclínicas, la de curso evolutivo benigno identificado como típico y la susceptible de transformación maligna, identificada como atípico. Histológicamente, la degeneración vacuolar del estrato basal del epitelio es el signo histomorfológico patognomónico seguido de apoptosis celular. La apoptosis es un evento esencial entre los fenómenos del ciclo celular, sucede con la finalidad de eliminar células dañadas o inútiles. De todas las proteínas implicadas las caspasas son los responsables de la ejecución de este mecanismo, especialmente la caspasa 3 por fragmentar y activar otras caspasas responsables de la proteólisis. El potencial de transformación maligna del LPO podría estar en relación con el fallo de este mecanismo de regulación del ciclo de las células epiteliales agredidas y la persistencia de células dañadas. El presente trabajo de investigación tuvo como objetivo analizar la presencia y proporción de apoptosis en las distintas variantes de LPO con técnicas histológicas de rutina y posterior aplicación de inmunohistoquímica, utilizando como marcador la caspasa 3. Se obtuvieron 20 biopsias de LPO de cinco variedades clínicas nueve variantes típicas (VT): cinco placa, cuatro reticulares y 11 variantes atípicas (VA): dos atróficos, seis erosivos, tres ampollares. El método de evaluación fue semicuantitativo, se consideró en función del porcentaje, se realizó un recuento celular de un total de 100 células en cinco campos de gran aumento

\section{ABSTRACT}

Autoimmune diseases have multiple manifestations in stomatology, among the most frequent is oral lichen planus (LPO), it is a chronic disease with clinical manifestations in skin and mucous membranes. It is grouped into two anatomoclinic forms, the benign evolutionary course identified as typical and susceptible to malignant transformation, identified as atypical. Histologically, vacuolar degeneration of the basal stratum of the epithelium is the pathognomonic histomorphological sign followed by cellular apoptosis. Apoptosis is an essential event among cell cycle phenomena, it happens in order to eliminate damaged or useless cells. Of all the proteins involved, caspases are responsible for the execution of this mechanism, especially caspase-3 for fragmenting and activating other caspases responsible for proteolysis. The potential for malignant transformation of the LPO could be related to the failure of this mechanism to regulate the cycle of attacked epithelial cells and the persistence of damaged cells. This research work aimed to analyze the presence and proportion of apoptosis in the different variants of LPO with routine histological techniques and subsequent application of immunohistochemistry, using caspase as a marker 3. 20 LPO biopsies from 5 clinical varieties were obtained 9 typical variants (VT): 5 plate, 4 reticular and 11 atypical variants (VA): 2 atrophic, 6 erosive, 3 ampoules. The evaluation method was semi-quantitative considering the percentage, making a cell count of a total of 100 cells, in five large-scale fields considering the following categories according to absence, mild presence $(<10 \%)$, moderate $(10 \leq 25 \%)$, intense $(25$ $\leq 50 \%$ ), not valuable. We found a good correlation of histological

\footnotetext{
* Odontóloga. Especialista en Docencia Universitaria. Becaria de Investigación de Postgrado de la Secretaría General de Ciencia y Técnica, Docente Auxiliar de la Cátedra de Anatomía Patológica de la Facultad de Odontología de la Universidad Nacional del Nordeste.

¥ Odontólogo. Especialista en Metodología de la Investigación. Profesor adjunto de la Cátedra Clínica Estomatológica e Integrante del Servicio de Clínica Estomatológica de la Facultad de Odontología de la Universidad Nacional del Nordeste.

$\S$ Médica. Especialista en Anatomía Patológica. Jefa del Servicio de Inmunohistoquímica Alexander Fleming. Jefa de Laboratorio privado de Anatomía Patológica e Inmunohistoquímica.

\| Odontólogo. Especialista en Docencia Universitaria. Docente Investigador dedicación exclusiva, Auxiliar de la Cátedra de Anatomía Patológica de la Facultad de Odontología de la Universidad Nacional del Nordeste.

ף Médica. Especialista en Anatomía Patológica. Profesor Titular de la Cátedra de Anatomía Patológica y Jefa del Servicio de Anatomía Patológica de la Facultad de Odontología de la Universidad Nacional del Nordeste.
} 
considerando las siguientes categorías según ausencia, presencia leve $(<10 \%)$, moderada $(10 \leq 25 \%)$, intensa $(25 \leq 50 \%)$, no valorables. Se encontró una buena correlación de los cambios histológicos y el grado de expresión del marcador utilizado para poner en evidencia la apoptosis, sobre todo con las muestras de LPO de variante atípica. En los casos de las variantes atípicas de liquen observados en comparación con la tinción de rutina (H/E) se observó igualdad o una disminución en algunos casos del número de queratinocitos apoptóticos. En cuanto a las variantes clínicas consideradas «típicas» se observó que el recuento de células en apoptosis estaba significativamente elevado. Obtuvimos excelentes resultados con el inmunomarcador caspasa 3 , el cual coincide con la literatura en su alta sensibilidad como recurso para cuantificar el número de apoptosis en estas lesiones orales.

Palabras clave: Liquen, malignización, marcadores apoptóticos. changes and the degree of expression of the marker used to highlight apoptosis, especially with the atypical variant LPO samples. In the cases of atypical variants of lichen observed, compared with routine staining $(H / E)$ we find equality or a decrease in some cases of the number of apoptotic keratinocytes. For clinical variants considered «typical» it was observed that the cell count in apoptosis was significantly increased. We obtained excellent results with the caspase 3 immunomarker coinciding with the literature of its high sensitivity as a resource to quantify the number of apoptosis in these oral lesions.

Keywords: Lichen, malignant, immunological markers apoptosis.

\section{INTRODUCCIÓN}

L as enfermedades autoinmunes tienen múltiples manifestaciones en estomatología, entre las más frecuentes se encuentra el liquen plano oral (LPO). Se trata de una enfermedad crónica con manifestaciones clínicas en piel y mucosas, en algunos casos se pueden observar lesiones en mucosa genital; afecta principalmente a mujeres en edad menopáusica. Tiene aspectos clínicos e histológicos característicos, se agrupa en dos formas anatomoclínicas, la de curso evolutivo benigno identificado como típico y la susceptible de transformación maligna, identificada como atípicos. ${ }^{1}$

El LPO es un desorden del epitelio escamoso con mayor incidencia en el sexo femenino ${ }^{2}$ en pacientes de edad media, y cobra mayor importancia por su facultad de transformación maligna. Es imperativa la diferenciación propuesta por la OMS respecto al liquen plano oral (LPO) de las lesiones liquenoides orales (OLL). Es importante consignar que ambas entidades son consideradas facultativamente cancerizables. ${ }^{3}$

La etiología del liquen sigue siendo desconocida, no así los mecanismos patogénicos, pues se sabe que las células basales de la epidermis y de la mucosa son dañadas por un proceso de tipo inmunitario mediado por linfocitos T citotóxicos (CD8+) y un número menor de linfocitos $T$ colaboradores que migran al lugar. La destrucción celular se produce por citotoxicidad directa por perforina y otras enzimas que se liberan de los linfocitos o por secreción de factor de necrosis tumoral u otras citocinas. Se produce muerte celular por apoptosis, esto determina menor número de células en condiciones de reparar, lo que condiciona adelgazamiento del epitelio. Se ve afectada también la producción de membrana basal y la señalización entre el tejido conjuntivo del corion y las células epiteliales que va influir en los mecanismos de unión del epitelio predisponiendo a que éste se separe. Este epitelio adelgazado se queratiniza.

Las lesiones epiteliales y las señales transmitidas por las citocinas atraen más linfocitos al lugar que se dispone en banda por debajo del epitelio. Este infiltrado es más mixto que el identificado en el epitelio y predominan aquí los linfocitos T colaboradores CD4 + y en menor proporción los linfocitos T citotóxicos CD8+. Cuando predominan los fenómenos de destrucción celular el epitelio se atrofia, se despega y se ulcera, se agrega inflamación inespecífica y se agrava la sintomatología. Cuando el episodio cede, las células que sobreviven proliferan y se recuperan, el epitelio se engruesa y queratiniza mucho. No está claro cuáles son las causas de esta evolución cíclica, pero los pacientes con frecuencia refieren estrés y traumatismos, incluidos tratamientos odontológicos como posibles factores que producen estos brotes.

La presentación clínica del LPO en un tercio de los casos es cutánea exclusivamente, otro tercio sólo son lesiones orales y el tercio restante, ambas. La presentación cutánea suele ser como pápulas de 2 a $3 \mathrm{~mm}$ en una superficie brillante caracterizada por diminutas «estrías de Wickham», pruriginosas y localizadas en superficies flexoras de antebrazo, muñecas, piernas y espalda.

El LPO se presenta clínicamente de tres formas anatomoclínicas, entre las que se distinguen las formas diferentes: reticular, eritematosa o atrófica, erosiva, ulcerada o ampollar. ${ }^{4}$

Las lesiones estomatológicas típicas se presentan bilateralmente simétricas en la reticular, con líneas blanquecinas finas causadas por la queratinización, de 1 a $2 \mathrm{~mm}$ que se entrecruzan al azar formando un patrón radiado, 
anular o entrelazado, en ocasiones con algunas pápulas blanquecinas diminutas. En la lesiones atróficas hay áreas rojizas por el adelgazamiento epitelial que muchas veces se entremezclan con las estrías. ${ }^{5}$ La localización en la mucosa yugal retrocomisural posterior es la más frecuente, seguida de las localizadas en la lengua, encía, mucosa labial y bermellón del labio inferior.

La forma clínica de placas son áreas sólidas de queratinización, afectan sobre todo el dorso de la lengua o la mucosa vestibular y plantean diagnóstico diferencial con leucoplasias. En la ampollar se da por separación del epitelio secundaria a la muerte por apoptosis de las células basales y debilitamiento de la membrana basal, cuya localización más frecuente suele ser la mucosa de la encía, donde es más fácil que se produzcan las lesiones ampollares que rápidamente se rompen y dan lugar a úlceras; deben diferenciarse de otras lesiones ampollares de la boca.

Las lesiones típicas suelen ser asintomáticas, a veces en su presentación atrófica y erosiva cursan con dolor, sensación de quemazón y con alteraciones funcionales como la disfagia y dificultad en el habla. Aproximadamente $10 \%$ de los pacientes presentan lesiones de tipo atrófico y erosivo. ${ }^{6}$ Para el tratamiento de la sintomatología asociada se indica el empleo de corticosteroides, preferentemente en forma tópica, reservando los sistémicos para los casos más graves, ${ }^{7}$ se recomienda además la eliminación de focos sépticos, un adecuado mantenimiento de la higiene oral y la eliminación de factores traumáticos.

Este trastorno de la mucosa oral es de carácter inflamatorio crónico con periodos de exacerbación y remisión, que es responsable de las diferentes formas de presentación o fases de la enfermedad, existe controversia sobre la posibilidad de transformación maligna, la cual depende del grado de displasia existente. Las formas atróficas erosivas son las que tienen mayor potencialidad de sufrir una transformación maligna, varían de 0.4 a 5\% en periodos de revisión variables de seis meses a 20 años, independiente del tipo clínico y del tratamiento. ${ }^{2,4}$

La mucosa oral afectada por el LPO histológicamente tiene características comunes que dependen de la variedad clínica de la enfermedad, puede presentar orto o paraqueratosis, acantosis, granulosis, espongiosis, cuerpos coloides, exocitosis linfocitaria y atrofia epitelial.

La intensa degeneración hidrópica vacuolar del citoplasma de las células basales es la responsable de la formación de ampollas subepiteliales identificadas como espacios de Max Joseph, se compone de un denso infiltrado inflamatorio celular difuso linfocitario en banda en contacto con la capa basal y la desaparición de la membrana basal Pas + por sectores, el infiltrado aludido integrado primariamente por macrófagos y linfocitos $T$ del tipo CD4+. Además pueden observarse células de Langerhans responsables de la lisis celular por intermedio de la presentación de antígenos necesarios para la función de los linfocitos.

Es así que la degeneración vacuolar del estrato basal del epitelio es el signo histomorfológico patognomónico seguido de apoptosis celular, que se define por la presencia de condensación cromática del núcleo, citoplasmática, picnosis nuclear y fragmentación nuclear. ${ }^{8-12}$ Se ha demostrado además la presencia de cuerpos de Civatte, identificados como elementos hialinos esferoidales homogéneos Pas+, resultantes de la apoptosis prematura de queratinocitos basales. En el epitelio se aprecian hiperqueratosis y acantosis en grado variable. ${ }^{11}$

La apoptosis es un evento esencial entre los fenómenos del ciclo celular, es un evento celular por el cual las células que mueren cumplen un rol preponderante en su eliminación. Esta forma de muerte celular programada sucede habitualmente en los organismos pluricelulares con la finalidad de eliminar células dañadas o inútiles sin repercusión en las células vecinas. ${ }^{13,14}$ Se activa por medio de la acción de proteasas específicas y de endonucleasas; es un proceso fisiológico que produce la condensación y

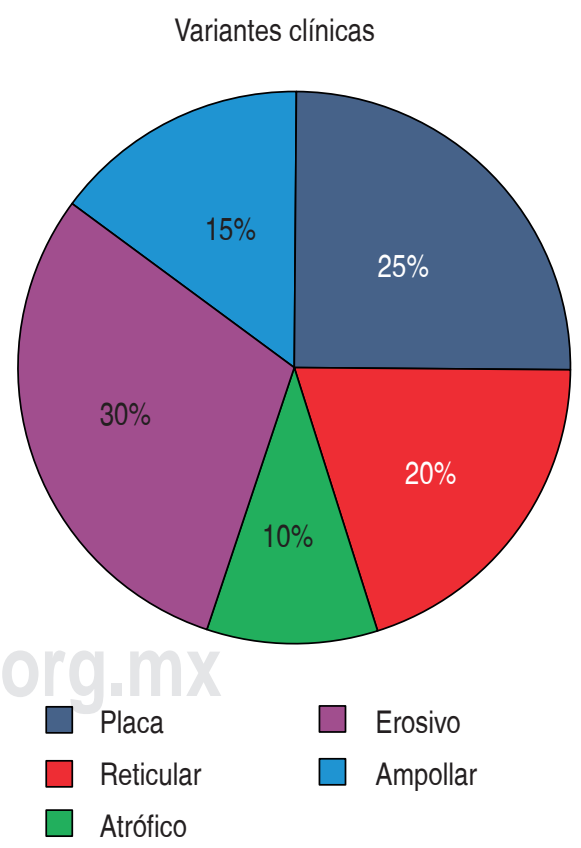

Figura 1: Porcentaje de las variantes clínicas de liquen plano oral obtenidas. 


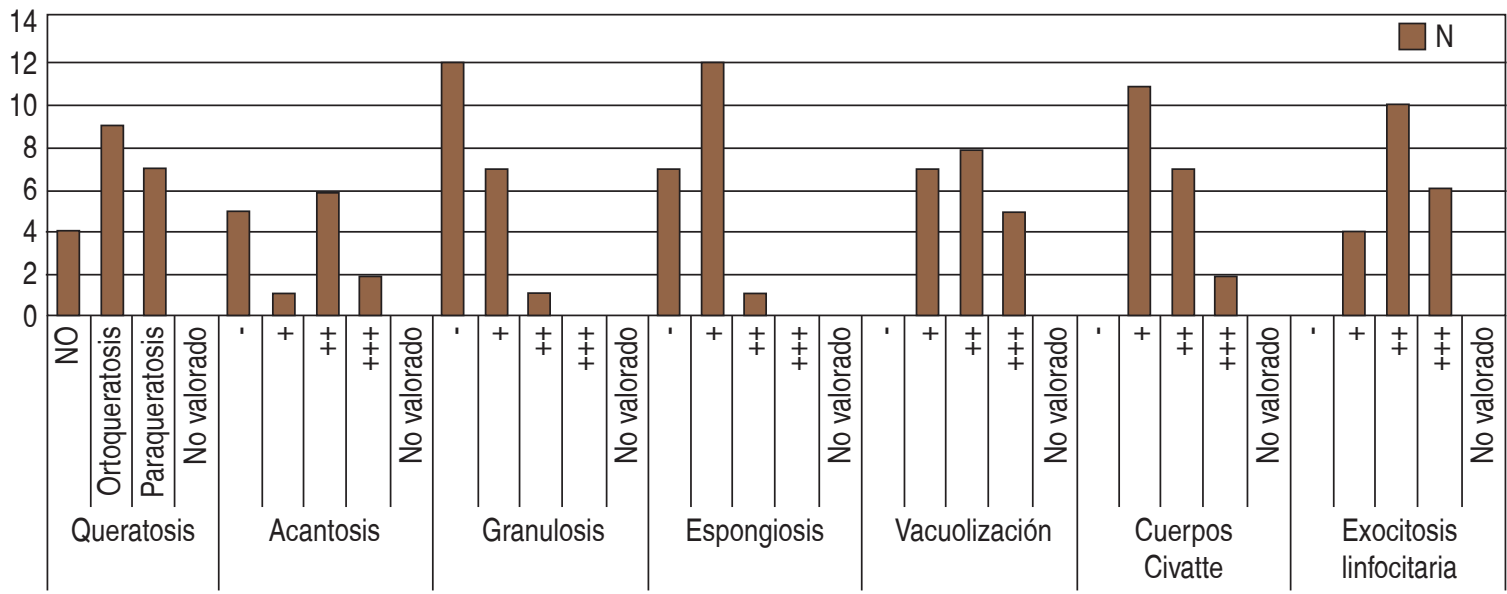

Degeneración vacuolar

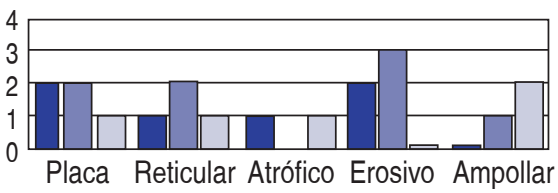

Leve $\square$ Moderada $\square$ Intensa
Cuerpos Civatte

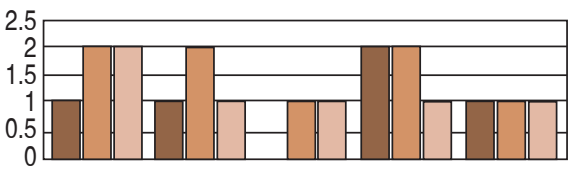

Placa Reticular Atrófico Erosivo Ampollar

$\square$ Leve $\square$ Moderada $\square$ Intensa
Infoltrado inflamatorio

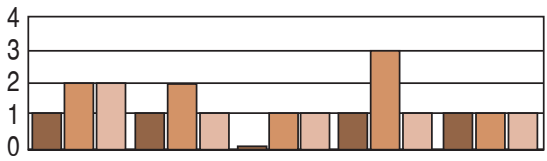

Placa Reticular Atrófico Erosivo Ampollar

$\square$ Leve $\square$ Moderada $\square$ Intensa
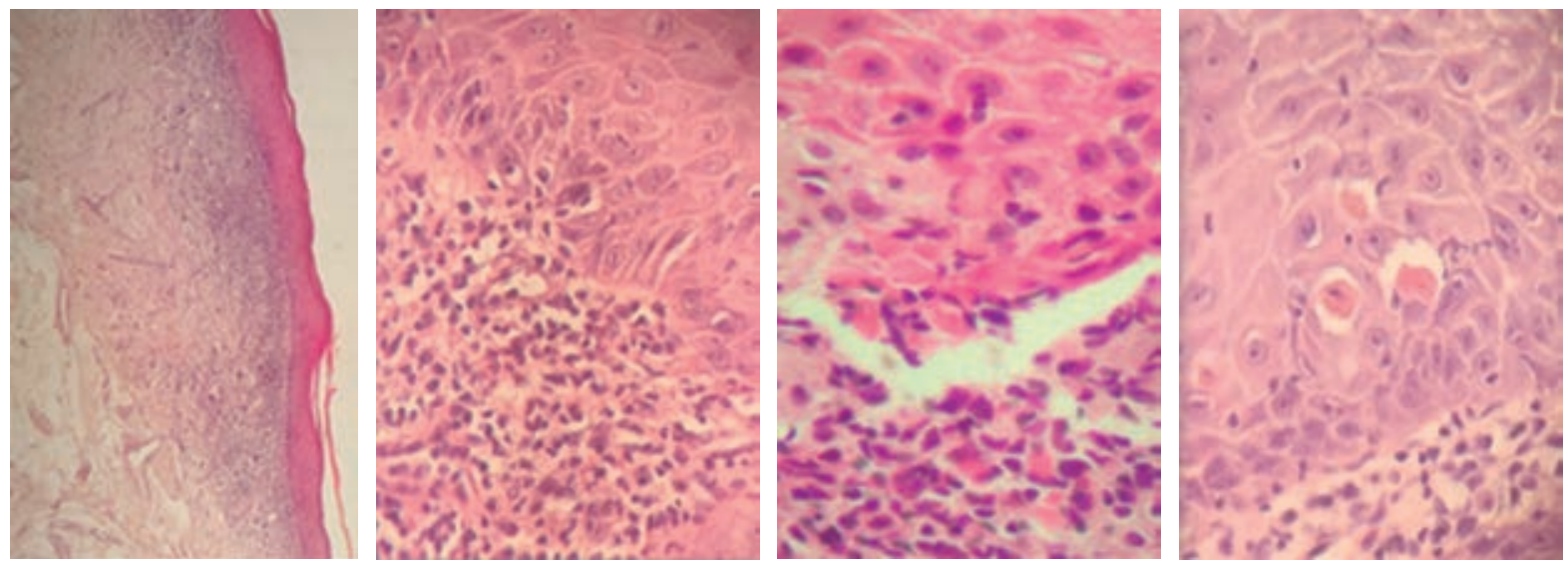

Figura 2: Valores histológicos de los parámetros obtenidos por microscopia óptica con la técnica de rutina (hematoxilina/eosina) tomando en cuenta queratosis, acantosis, granulosis, espongiosis, degeneración hidrópica, cuerpos de Civatte y exocitosis linfocitaria. Se especifican el tipo clínico de liquen obtenido con estos tres últimos parámetros y se ejemplifica con microfotografías al MO al 10x 40x y 100x.

fragmentación de la cromatina y formación de cuerpos apoptóticos. El proceso apoptótico cursa varias etapas, en la primera de ellas, la célula pierde el contacto con las células vecinas, permitiendo la formación de prominencias en la membrana plasmática, posteriormente se condensa y fragmenta la cromatina, permaneciendo la envoltura nuclear, en consecuencia disminuye el volumen citoplasmático producto de la condensación de las proteínas y la pérdida de agua. En la segunda etapa se fragmenta la membrana plasmática, aparecen los cuerpos apoptóticos que contienen material nuclear y citoplasmático. Luego en la tercera etapa finalmente los macrófagos fagocitan y degradan los cuerpos apoptóticos. Las caspasas son las responsables de la activación del mecanismo en los mamíferos, específicamente se trata de proteasas, de la familia de las cistein-proteasas, en especial la caspasa 3 
por fragmentar y activar otras caspasas responsables de la proteólisis. ${ }^{15}$ Otro inductor de la apoptosis pertenece al grupo Bcl-2, la forma que activa la apoptosis es Bax-a. ${ }^{16}$

Mediante la técnica TUNEL (transfer uridine nick-end labelling) se detecta la fragmentación del ADN en escalera en los núcleos apoptóticos; es un método que permite,

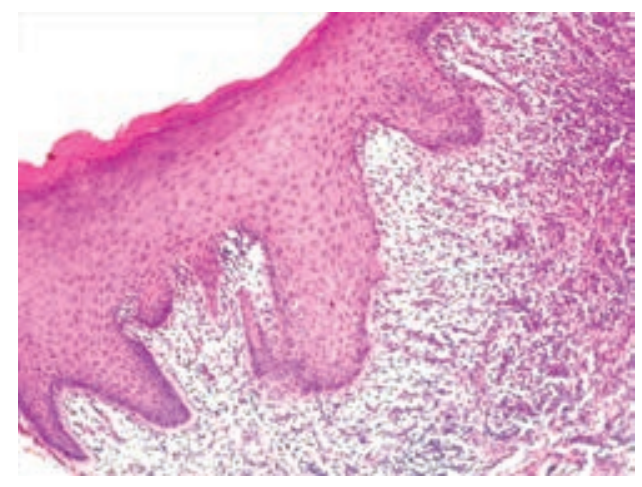

Figura 3: Variante clínica reticular H/E MO 100x.

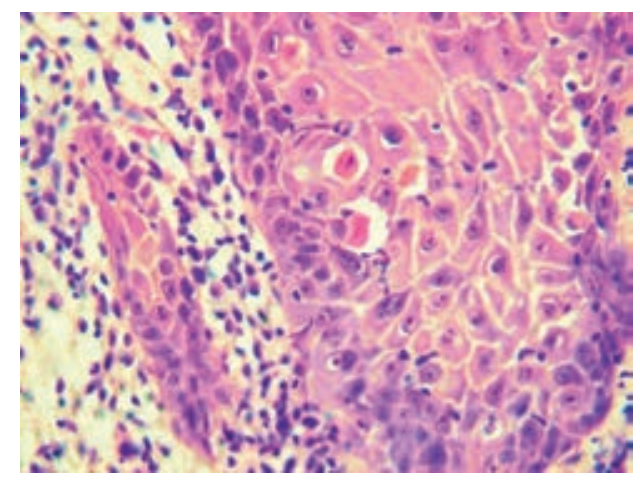

Figura 4: Variante clínica reticular H/E MO 400x.

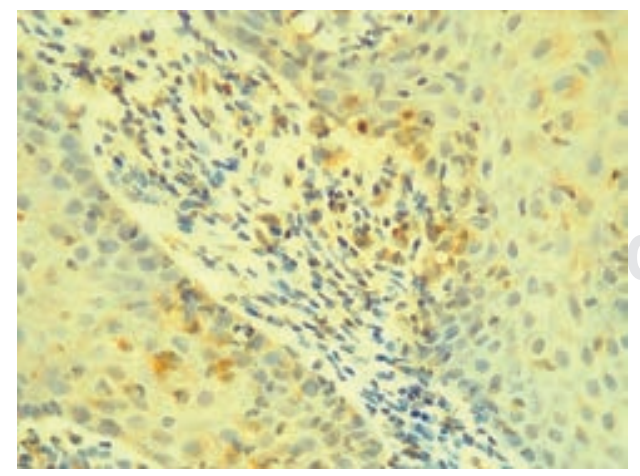

Figura 5: Variante clínica reticular IHQ caspasa-3 MO 400x.

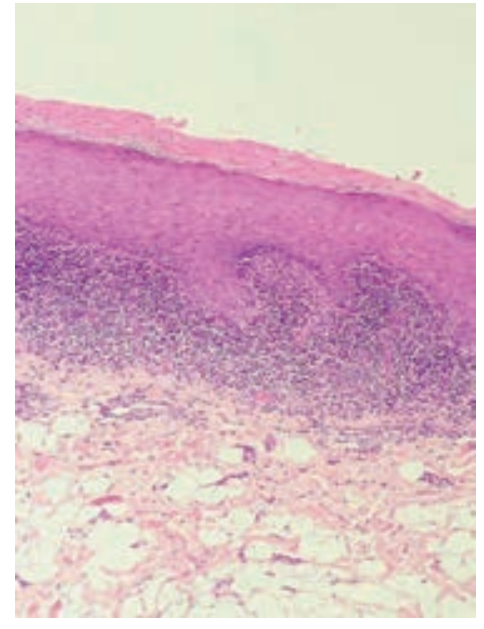

Figura 6: Variante clínica en placa H/E MO 100x.

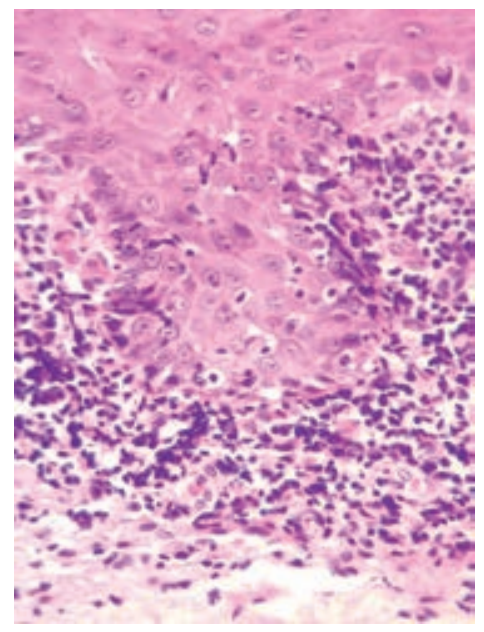

Figura 7: Variante clínica en placa H/E MO 400x.

de forma rápida y sencilla, la detección de apoptosis en células de cultivos celulares. ${ }^{17}$

De todas las proteínas implicadas en la activación y ejecución de apoptosis, las proteasas similares a ICE o las caspasas (14 identificadas hasta ahora en humanos) se destacan por ser cruciales para este proceso en diversos organismos. ${ }^{18,19}$

En los mamíferos, las caspasas (principalmente la caspasa 3) parecen activarse en una cascada de proteasas que conduce a una activación inapropiada o una rápida desactivación de las proteínas estructurales clave y de la señalización, homeostasia y reparación enzimática. ${ }^{18}$ Es con frecuencia una proteasa de muerte 


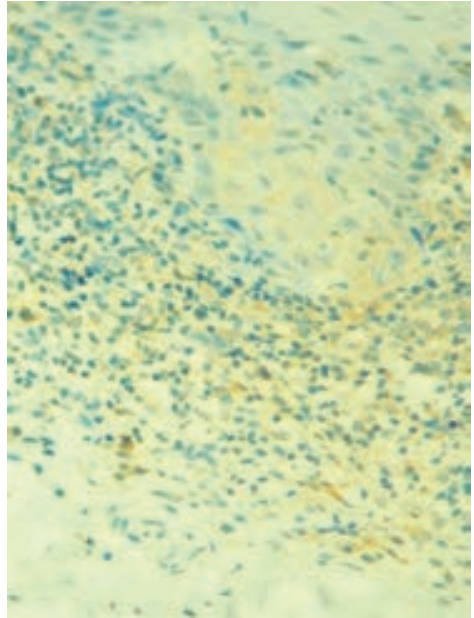

Figura 8: Variante clínica en placa IHQ caspasa-3 MO 400x.

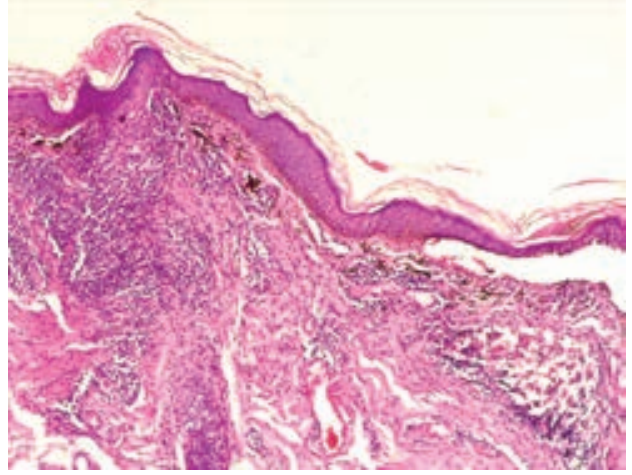

Figura 9: Variante clínica ampollar H/E MO 100x.

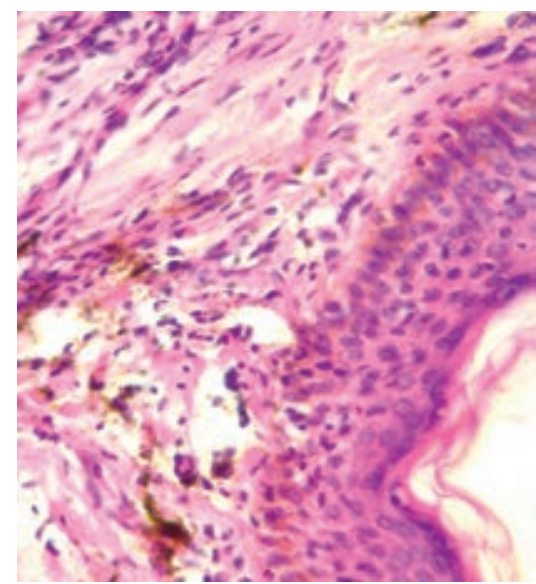

Figura 10: Variante clínica ampollar H/E MO 400x.

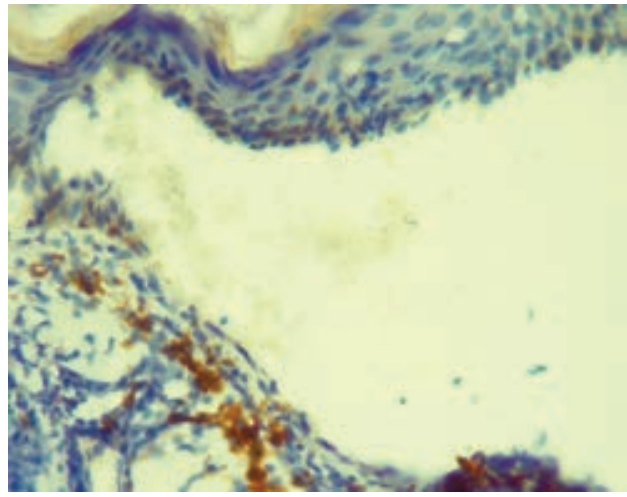

Figura 11: Variante clínica ampollar IHQ caspasa-3 MO 400x.

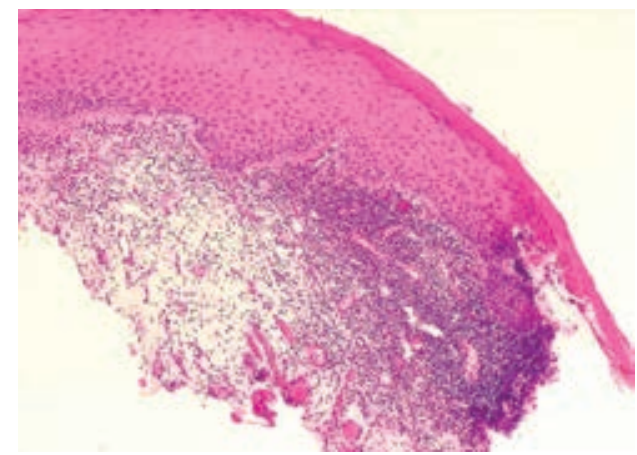

Figura 12: Variante erosiva H/E MO 100x.

activada que cataliza la escisión específica de muchas proteínas celulares clave, la caspasa 3 es importante para la muerte celular en un tejido, tipo celular o forma específica de estímulo de muerte, y es esencial para algunos de los cambios característicos en la morfología celular y ciertos eventos bioquímicos asociados con la ejecución y finalización de la apoptosis. La caspasa 3 es probablemente el mejor marcador de apoptosis en los mamíferos debido a su especificidad y roles que desempeña. ${ }^{20}$

Ciertas alteraciones en estos mecanismos de control celular en los epitelios estarían implicadas en la génesis de carcinoma oral de células escamosas (COCE) relacionadas con el LPO. ${ }^{8}$ Actualmente se sostiene que algunas moléculas y radicales libres producidos por las células inflamatorias del LPO pueden actuar como agentes que inducen mutaciones a las células epiteliales o ejercer una significativa influencia en los elementos de regulación del ciclo celular como la apoptosis. ${ }^{9}$ 
La probable transformación maligna se asocia a niveles elevados de ansiedad, al grado de depresión y a un aumento de la susceptibilidad a desórdenes psíquicos, especialmente en las formas erosivas de presentación. ${ }^{4}$ Se cimienta por los elevados niveles de cortisol salival inducidos por el estrés. ${ }^{10}$

Otros fenómenos moleculares importantes que acontecen en la regulación del ciclo celular son la detención del ciclo celular y la senescencia celular, que permite que se reparen los daños en el ADN. La senescencia conduce a la muerte celular por un mecanismo diferente a la apoptosis. Las células senescentes en cultivo conservan un número limitado de divisiones celulares que han perdido su capacidad de proliferación habiendo llegado al límite de su vida replicativa.

En relación a los acontecimientos moleculares reguladores o estimuladores del ciclo celular en el liquen

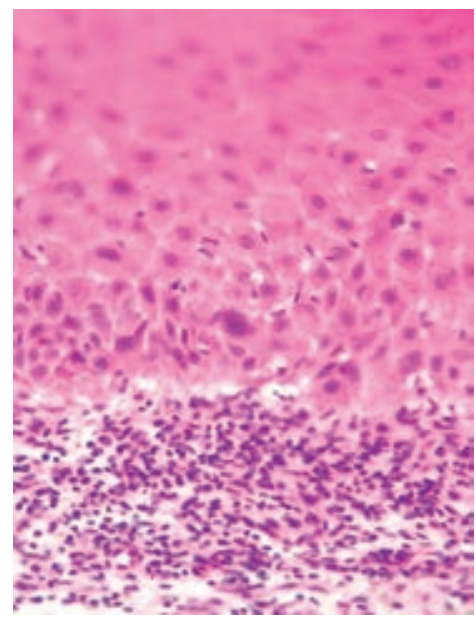

Figura 13: Variante erosiva H/E MO 400x.

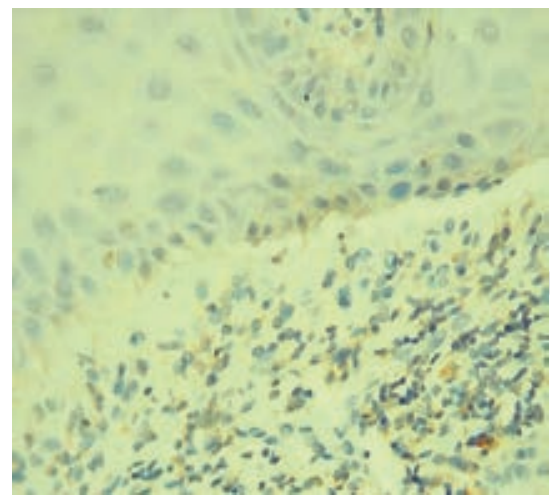

Figura 14: Variante erosiva IHQ caspasa-3 MO 400x.

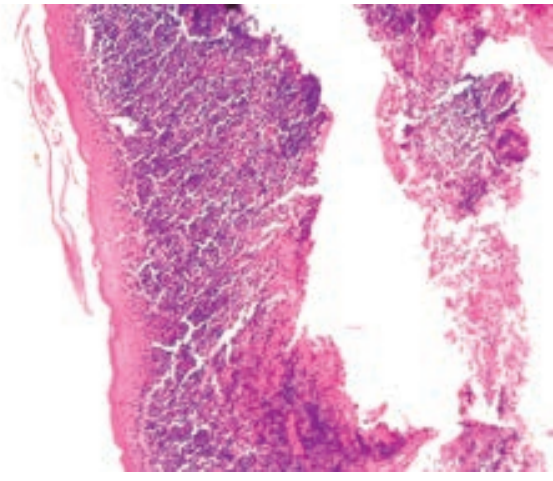

Figura 15: Variante atrófica H/E MO 100x.

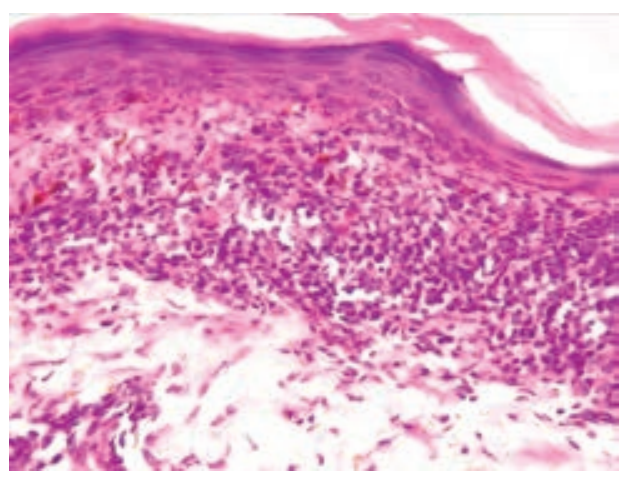

Figura 16: Variante atrófica H/E MO 400x.

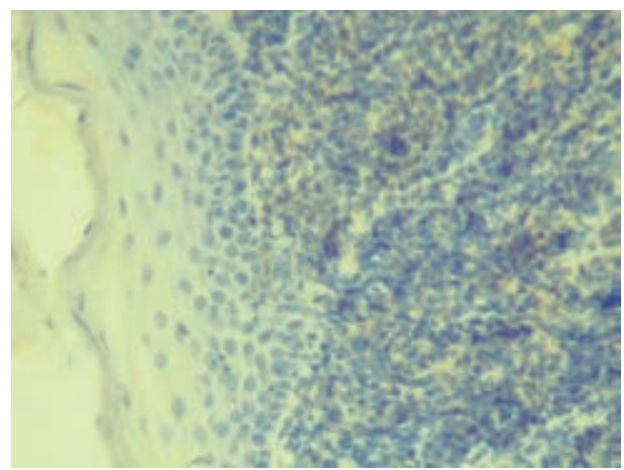

Figura 17: Variante atrófica IHQ caspasa-3 MO 400x.

plano oral, diversas publicaciones han comunicado que las células agredidas desarrollan mecanismos moleculares encaminados a detener el ciclo celular para reparar el ADN, inducir a senescencia celular o a apoptosis para eliminar las células con ADN severamente lesionadas. 


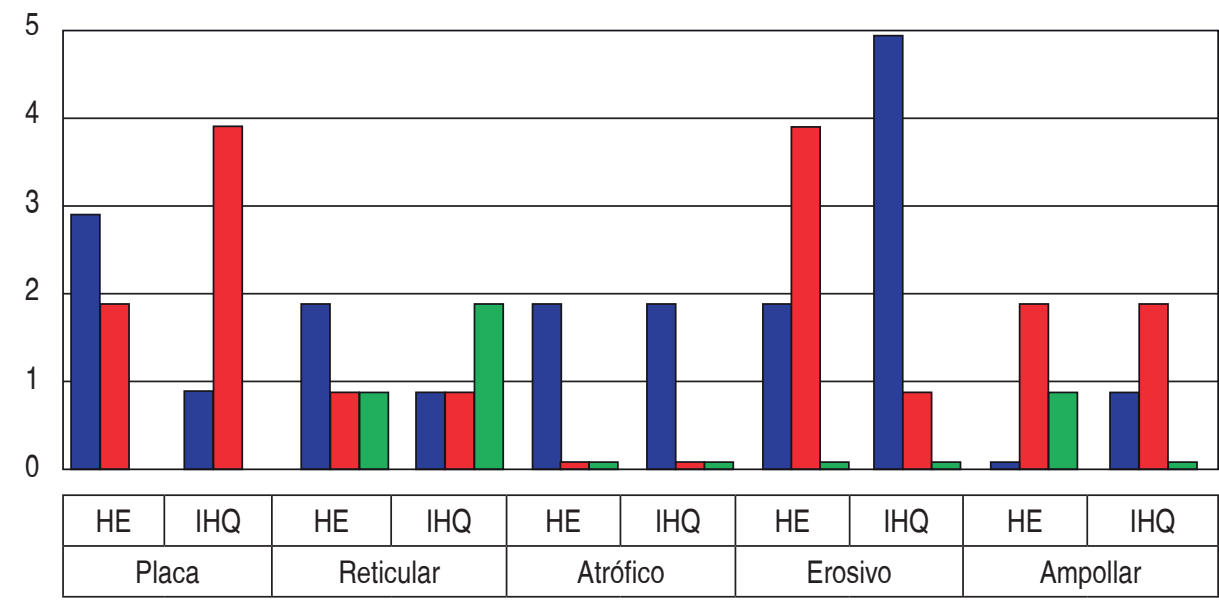

Figura 18:

Células en apoptosis en las diferentes variantes clínicas comparando técnica histológica de rutina con hematoxilina/ eosina (H/E) y la técnica de inmunohistoquímica (IHQ) con caspasa.

Leve

Moderada

Intensa

Por otra parte, otros autores también han demostrado que las células epiteliales en el LPO con frecuencia responden al ataque $\mathrm{T}$ - linfocitario con un incremento de los índices de proliferación celular. Desde nuestro punto de vista, resulta sorprendente e inesperada la concurrencia en el epitelio oral afectado por LP de mecanismos moleculares que pueden detener el ciclo celular, inducir apoptosis y estimular la proliferación celular. $^{21}$

El potencial de transformación maligna del LPO podría estar en relación con los fenómenos contradictorios que acontecen en la regulación del ciclo de las células epiteliales agredidas.

El presente trabajo de investigación tuvo como objetivo analizar la presencia y proporción de apoptosis en las variantes de LPO con técnicas histológicas de rutina y posterior aplicación de inmunohistoquímica usando como marcador la caspasa 3.

\section{MATERIAL Y MÉTODOS}

Sobre un tamaño de muestra de 20 biopsias orales de LPO obtenidas se registraron sus respectivos antecedentes clínicos. Luego las muestras se fijaron en formol-buffer y se procesaron con la técnica de rutina de inclusión en parafina, coloración de hematoxilina/ eosina para aplicar posteriormente la técnica inmunohistoquímica.

Se realizó la observación y registro de todas las muestras con microscopia óptica a 40x, 100x y 400x. Se identificaron las diferentes variantes de liquen y los resultados observados fueron volcados en planillas, determinando el grado de apoptosis de los diferentes tipos de liquen.

En el análisis histopatológico se consideraron: queratosis, acantosis, granulosis, espongiosis, degeneración vacuolizante de la capa basal del epitelio, cuerpos de Civatte, exocitosis linfocitaria e infiltrado inflamatorio subepitelial en banda.

El método de evaluación fue semicuantitativo considerándose en función del porcentaje, se realizó un recuento celular de un total de 100 células en cinco campos de gran aumento considerando las siguientes categorías: ausencia, presencia leve $(<10 \%)$, moderada $(10 \leq 25 \%)$, intensa $(25 \leq 50 \%)$ y no valorables.

Se observó la morfología de la unión epitelio conectiva considerándose: plana, papilar, no valorable. Se considera la presencia o ausencia de despegamientos epiteliales.

Se seleccionaron y enviaron los casos para ser sometidos a inmunohistoquímica para aplicar la técnica de inmunomarcación propuesta. Se realizó inmunomarcación para la detección de caspasa 3 en cortes de bloques incluidos en parafina de material fijado en formol-buffer.

La técnica recomienda hacer cortes delgados, los cuales deben levantarse en el portaobjeto y posteriormente se realiza el desparafinado y rehidratación. Se realizó la recuperación antigénica con el tratamiento de los cortes en horno de microondas con buffer de citrato utilizando los portaobjetos con adhesivo y el sistema de detección biotina-estreptavidina-peroxidasa (BioGenex).

Se utilizó el siguiente anticuerpo: caspasa 3 (PharMingen ${ }^{\circledR}$ ) para la valoración de la expresión del marcador, se evaluaron los resultados de la técnica inmunohistoquímica según positividad o negatividad de la marcación. Se comparó \% de células en apoptosis entre técnica de rutina y la IHQ.

Como control positivo se utilizó una biopsia de infarto renal. Como control negativo se utilizó una muestra incubada con el buffer sin el anticuerpo. 


\section{RESULTADOS}

Se obtuvieron 20 biopsias de LPO de cinco variedades clínicas:

Nueve variantes típicas (VT): cinco placas y cuatro reticulares.

Once variantes atípicas (VA): dos atróficos, seis erosivos, tres ampollares (Figura 1).

De las cuales pudimos observar una proporción de: paraqueratosis leve $60 \%$ y ortoqueratosis leve $75 \%$; acantosis leve, moderada y severa en $30 \%$; granulosis ausente en $60 \%$ y espongiosis leve en $60 \%$ de los casos; la degeneración vacuolar leve $35 \%$ a moderada $40 \%$ y cuerpos de Civatte en proporción leve 55\%, moderada $35 \%$ y severa $10 \%$. El infiltrado en banda fue moderado en $50 \%$ y severo $30 \%$ (Figura 2). Además, una de las variantes de liquen erosivo presentó cambios displásicos leves a nivel del estrato basal y en otra variante ampollar se encontraron inclusiones de HPV. Destacándose en la valoración histológica con $\mathrm{H} / \mathrm{E}$, las VA presentaron un recuento de cuerpos de Civatte leve, mientras que en las VT encontramos una proporción en predominio moderada e intensa de queratinocitos apoptóticos.

Realizamos la técnica de inmunohistoquímica con el marcador Caspasa 3, los resultados arrojaron datos esperados y, en algunos casos, incluso mejoraron las expectativas. Para las variantes clínicas consideradas «típicas » se observó que el recuento de células en apoptosis estaba significativamente aumentado, sobre todo en el caso de la variante reticular (Figuras 3 a 5), donde los resultados con técnicas de rutina tuvieron un predominio dentro de la categoría leve y luego, con la aplicación de IHQ, se visualizó un porcentaje aumentado de células que expresaban el marcador, pasando a la categoría intensa, al igual que en la variante en placa (Figuras 6 a 8), que de presentar valores dentro de la categoría leve, con la aplicación de IHQ, aumentó el porcentaje a moderado para el conteo de queratinocitos en apoptosis. En los casos de las variantes atípicas de líquenes observados, que incluyen las formas ampollares (Figuras 9 a 11), erosiva (Figuras 12 a 14) y atrófica (Figuras 15 a 17), comparando con la tinción de rutina $(H / E)$, encontramos igualdad o una disminución en algunos casos del número de queratinocitos apoptóticos, como por ejemplo, en la variante erosiva, que de un total de seis muestras donde habíamos consignado dos leves y cuatro moderadas con técnicas de rutina, se obtuvieron las siguientes categorías: cuatro leves y una moderada (Figura 18).

\section{DISCUSIÓN}

El estudio realizado por Aguado Gil JM, Rubio Flores D, denominado «Apoptosis y liquen plano oral. Situación actual», analizó el liquen plano oral susceptible de transformación maligna, en el cual se ha investigado la relación entre su patogenia y los mecanismos apoptóticos de destrucción celular y los diferentes marcadores utilizados para poner en evidencia la apoptosis. Las conclusiones de dicho estudio fueron las siguientes: 1) No hay consenso entre los diferentes autores sobre si el LPO es una patología con predominio de fenómenos apoptóticos. 2) No existe acuerdo sobre el marcador apoptótico que con más frecuencia se relaciona con el LPO. 3). Muy probablemente el proceso apoptótico se deba a una asociación de los tres ejes que activan la cascada de las caspasas. 4) Se precisan estudios a largo plazo con una amplia muestra que monitoricen la mayoría de los marcadores apoptóticos, buscando diferencias significativas entre las distintas formas clínicas, la patogenia, la evolución y la malignización de los casos con LPO.

Según nuestras observaciones la correlación de los cambios displásicos de las lesiones coincide en 100\% con las muestras de LPO de variante atípica

Obtuvimos buenos resultados con el inmunomarcador caspasa 3 coincidiendo con varios autores de la especificidad de este marcador como mejor recurso para estudiar el número de apoptosis en estas lesiones orales, en comparación con lo observado con técnicas de rutina. Sin embargo, no podemos dejar de admitir que son necesarios estudios a largo plazo y con mayor número de casos para poder apreciar diferencias significativas entre las distintas formas clínicas, la patogenia, la evolución y la malignización de los casos con LPO, tal y como lo sugiere el estudio de Aguado Gil JM y Rubio Flores D.

Se plantean dificultades para valorar el riesgo de transformación del LPO; en primer lugar, el LPO presenta rasgos característicos, pero no específicos a nivel clínico e histopatológico. En segundo lugar, muchos tipos de liquen no se biopsian perdiéndose la posibilidad de valorar la presencia o ausencia de displasia. Muchas lesiones leucoplásicas se parecen a formas de liquen en placa. Quizás muchos casos informados como carcinomas originados en liquen plano se deban al hecho de confundir displasia leve en lesiones parecidas a liquen que corresponderían a estadios precoces de leucoplasia verrugosas proliferativas. No se han identificado factores de riesgo específicos y tanto las lesiones queratósicas como las atróficas parecidas al LPO podrían dar origen a carcinomas. Las características de presentación clínica y localización, como los antecedentes de tabaquismo, son 
de suma importancia en la pesquisa temprana de lesiones que podrían evolucionar a carcinomas.

\section{CONCLUSIONES}

Encontramos una buena correlación de los cambios histológicos y el grado de expresión del marcador utilizado para poner en evidencia la apoptosis, sobre todo con las muestras de LPO de variante atípica. Obtuvimos excelentes resultados con el inmunomarcador caspasa 3, lo que coincide con la literatura por su alta sensibilidad como recurso para cuantificar el número de apoptosis en estas lesiones orales. Podemos concluir que la mejora en el diagnóstico de los desórdenes orales potencialmente malignos como es el caso del LPO, la valoración de los cambios histomorfológicos y moleculares implicados en uno de sus aspectos como lo es la apoptosis, contribuyen a la mejor comprensión y naturaleza de los fenómenos implicados en esta patología, como también al conocimiento sobre factores con interés pronóstico que permitan identificar aquéllos con riesgo de evolucionar a lesiones potencialmente cancerizables para la aplicación de medidas y acciones pertinentes.

\section{AGRADECIMIENTOS (OPCIONAL)}

\section{Dra. Teresa Pombo, histotécnica de la FOUNNE Marcela Solís.}

\section{BIBLIOGRAFÍA}

1. Gupta S, Jawanda MK. Oral lichen planus: an update on etiology, pathogenesis, clinical presentation, diagnosis and management. Indian J Dermatol. 2015; 60 (3): 222-229.

2. Olson MA, Rogers RS 3rd, Bruce AJ. Oral lichen planus. Clin Dermatol. 2016; 34 (4): 495-504.

3. García-Rubio A, Ibáñez-Romero MC. Capítulo 4: Lesión premaligna de la mucosa bucal: liquen plano oral. En: Molero MM, Pérez-Fuentes MC, Gázquez JJ, Simón MM, Martos A, Barragán AB. Acercamiento multidisciplinar a la salud. Volumen III. ASUNIVEP; 2018. p. 41.

4. López-López J, Omaña-Cepeda C, Jané-Salas E. Precáncer y cáncer bucal. Medicina Clínica. 2015; 145 (9): 404-408.

5. Maia HC, Pinto NA, Pereira Jdos S, de Medeiros AM, da Silveira Éj, Miguel MC. Potentially malignant oral lesions: clinicopathological correlations. Einstein (Sao Paulo). 2016; 14 (1): 35-40.

6. Scully C, Carrozzo M. Oral mucosal disease: lichen planus. $\mathrm{Br} J$ Oral Maxillofac Surg. 2008; 46: 15-21.
7. Alrashdan MS, Cirillo N, McCullough M. Oral lichen planus: a literature review and update. Arch Dermatol Res. 2016; 308 (8): 539-551.

8. Gonzalez-Moles MA, Scully C, Gil-Montoya JA. Oral lichen planus: controversies surrounding malignant transformation. Oral Dis. 2008; 14 (3): 229-243.

9. Georgakopoulou E, Achtari M, Achtaris M, Foukas P, Kotsinas A. Oral lichen planus as a preneoplastic inflammatory model. J Biomed Biotechnol [Internet]. 2012 [citado julio de 2014]; 1: 1-8. Disponible en: http://www.ncbi.nlm.nih.gov/pmc/ articles/ PMC3362930/pdf/JBB2012-759626.pdf

10. Cok S, Cok CC, Bascones-Martínez A. Malignización del liquen plano oral (LPO). Av Odontoestomatol. 2015; 31 (5): 323-329.

11. Flores L, Senarega A, Innocenti C, Rivarola E. Liquen oral, patrones reaccionales liquenoides y cáncer oral: estudio clínico e histopatológico retrospectivo de 12 años. Dermatol Argent. 2016; 22 (1): 13-18.

12. Suganya G, Bavle RM, Paremala K, Makarla S, Sudhakar M, Reshma V. Survivin expression in oral lichen planus: Role in malignant transformation. J Oral Maxillofac Pathol. 2016; 20 (2): 234-238.

13. Sagari S, Sanadhya S, Doddamani M, Rajput R. Molecular markers in oral lichen planus: a systematic review. J Oral Maxillofac Pathol. 2016; 20 (1): 115-121.

14. Neppelberg E, Johannessen AC, Jonsson R. Apoptosis in oral lichen planus. Eur J Oral Sci. 2001; 109 (5): 361-364.

15. Tobón-Arroyave SI, Villegas-Acosta FA, Ruiz-Restrepo SM, ViecoDurán B, Restrepo-Misas M, Londoño-López ML. Expression of caspase-3 and structural changes associated with apoptotic cell death of keratinocytes in oral lichen planus. Oral Dis. 2004; 10 (3): 173-178

16. Atai Z, Khodadadi-Bohlouli Z, Navabi N. Molecular markers as an indicator in the malignant potential of oral lichen planus: a systematic review. J Oral Health Oral Epidemiol. 2017; 6 (2): 54-62.

17. Kyrylkova K, Kyryachenko S, Leid M, Kioussi C. Detection of Apoptosis by TUNEL Assay. In: Kioussi C (eds) Odontogenesis. Methods in Molecular Biology (Methods and Protocols). 2012.

18. Nicholson DW, Thornberry A. Caspases: killer proteases. Trends Biochem Sci. 1997; 22: 299-306.

19. Thornberry NA, Lazebnik Y. Caspases: enemies within. Science. 1998; 281: 1312-1316.

20. Porter AG, Jänicke RU. Emerging roles of caspase-3 in apoptosis. Cell Death Differ. 1999; 6 (2): 99-104.

21. Murray AW. Creative blocks; cell-cycle checkpoints and feedback controls. Nature. 1992; 359: 599-604.

Correspondencia:

Liset Eliana Osnaghi Díaz Colodrero

E-mail: lisetosnaghi@hotmail.com

María Susana Briend

E-mail: msbriend@odn.unne.edu.ar 